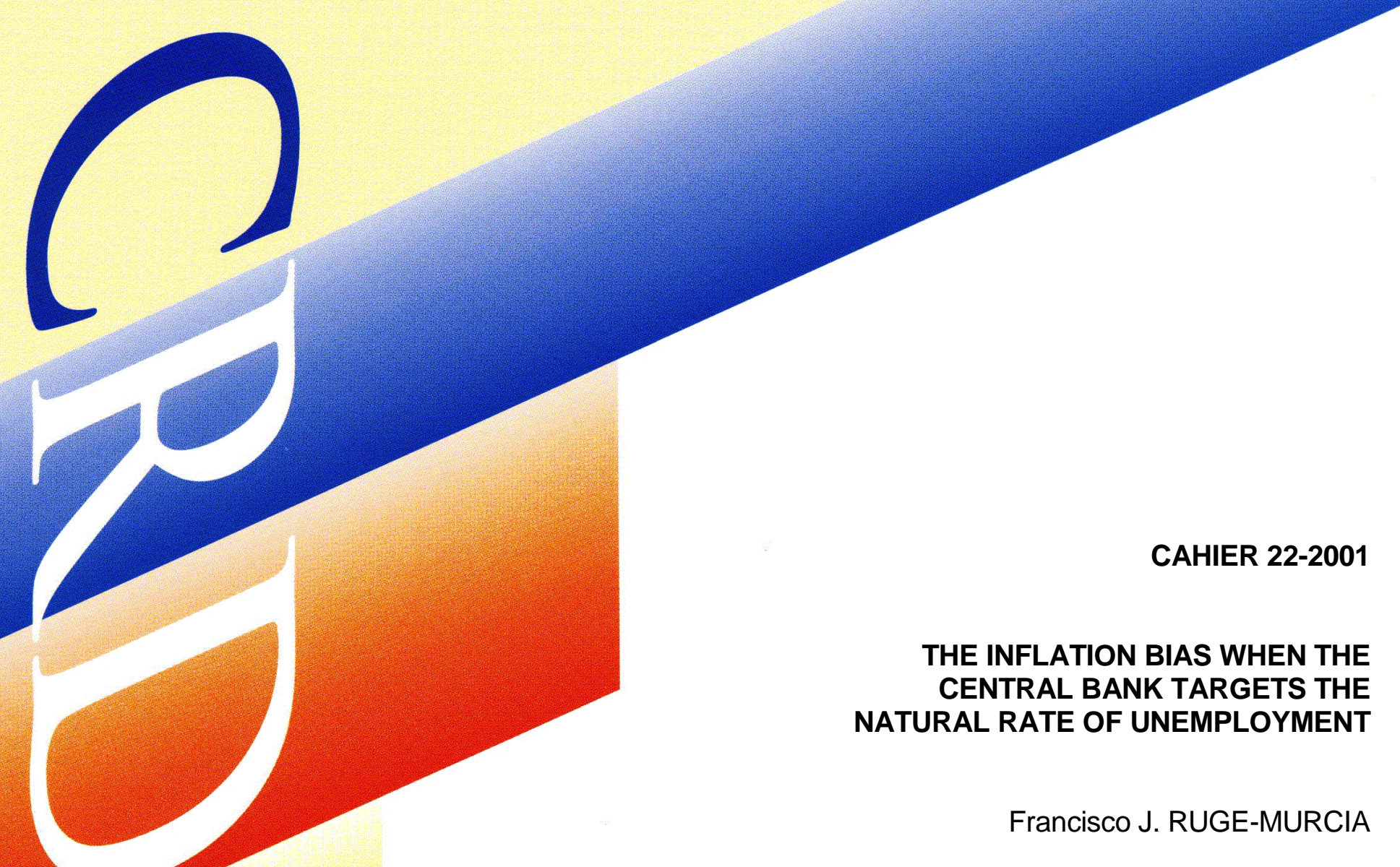

Centre de recherche et développement en économique

C.P. 6128 , succursale Centre-ville Montréal QC H3C 3J7 
CAHIER 22-2001

\title{
THE INFLATION BIAS WHEN THE CENTRAL BANK TARGETS THE NATURAL RATE OF UNEMPLOYMENT
}

\author{
Francisco J. RUGE-MURCIA ${ }^{1}$ \\ 1 Centre de recherche et développement en économique (C.R.D.E.) and Département \\ de sciences économiques, Université de Montréal
}

October 2001

This project was started while the author was visiting research fellow at the Bank of Spain in the spring of 2000. The author wishes to thank two anonymous referees for their comments and the Bank of Spain for its hospitality. Financial support from the Social Sciences and Humanities Research Council and the Fonds pour la formation de chercheurs et l'aide à la recherche is gratefully acknowledged. 


\section{RÉSUMÉ}

Cet article étudie la proposition qu'un biais inflationniste puisse survenir dans une situation où un banquier central ayant des préférences asymétriques cible le taux de chômage naturel. Les préférences sont asymétriques dans le sens que les écarts positifs du chômage par rapport au taux naturel sont pondérés plus (ou moins) sévèrement que les écarts négatifs dans la fonction de perte du banquier central. Le biais est proportionnel à la variance conditionnelle du chômage. Les prédictions du modèle sont évaluées en utilisant des données des pays du G7. Les estimations économétriques soutiennent la prédiction que la variance conditionnelle du chômage et le taux d'inflation sont reliés positivement.

Mots clés : biais inflationniste, préférences asymétriques

\section{ABSTRACT}

This paper studies the proposition that an inflation bias can arise in a setup where a central banker with asymmetric preferences targets the natural unemployment rate. Preferences are asymmetric in the sense that positive unemployment deviations from the natural rate are weighted more (or less) severely than negative deviations in the central banker's loss function. The bias is proportional to the conditional variance of unemployment. The time-series predictions of the model are evaluated using data from G7 countries. Econometric estimates support the prediction that the conditional variance of unemployment and the rate of inflation are positively related.

Key words : inflation bias, asymmetric preferences 


\section{Introduction}

This paper studies the proposition that an inflation bias can arise in a setup where a central banker with asymmetric unemployment preferences targets the natural rate. Preferences are asymmetric in the sense that positive unemployment deviations from the natural rate are weighted more (or less) severely than negative deviations in the central banker's loss function. Since the bias is proportional to the conditional variance of the rate of unemployment, the model generates testable cross-section and time-series implications. In a cross section, countries where unemployment is more variable or that are subject to more volatile supply shocks, should have a larger average rate of price inflation. Preliminary evidence supporting this hypothesis is provided by Gerlach (1999). In a time-series, periods of more volatile unemployment should be associated with a higher inflation rate. This prediction is formally examined here using data from G7 countries. Maximum Likelihood (ML) estimates support the hypothesis of asymmetric preferences for the United States and France, but not for Canada, Italy, or the United Kingdom.

Previous literature usually assumes that the central banker targets a rate of unemployment strictly below the natural rate. Among others, Persson and Tabellini (2000) note that this assumption is crucial in generating an inflation bias in the linear-quadratic framework of Kydland and Prescott (1977) and Barro and Gordon (1983). The view that the central banker targets a below-natural unemployment rate has been recently challenged on both theoretical and operational grounds. For example, McCallum (1995, 1997) argues that since, in equilibrium, unemployment equals the natural rate but inflation is larger than optimal, the central banker would eventually understand that the unemployment target is unobtainable and revise its goal. King (1996) and Blinder (1998) suggests on the basis of institutional evidence, that the monetary authority actually targets the expected natural rate of unemployment.

The observation that an inflation bias can arise even if the central banker targets the natural unemployment rate was first due to Cukierman (2000). Cukierman outlines two conditions (both of which are satisfied here) that are required to deliver the result: $(i)$ uncertainty about next period's realizations of inflation and unemployment and ( $i i$ ) asymmetric unemployment preferences. Using a specification of the loss function where the central banker cares about unemployment only when it is above the natural rate, he finds an inflation bias that is proportional to the probability of a recession. This paper employs a preference specification that nests the usual quadratic loss function as a special case, finds an inflation (or a deflation) bias that is proportional to the conditional variance of unemployment, constructs an econometric framework to examine the model predictions, and provides empirical evidence that the assumption of asymmetric preferences is plausible for some countries in the sample. Finally, this project complements research by Clarida, Galí, and Gertler (1999) who show that even when the unemployment target corresponds to the natural rate, there are gains from enhancing the central banker's credibility.

The paper is organized as follows: section 2 describes the economy and central banker's preferences, finds the subgame-perfect Nash equilibrium, derives conditions for the existence and uniqueness of the equilibrium, and examines the properties of the inflation bias; section 3 reports empirical estimates; and section 4 concludes. 


\section{The Model}

\subsection{The Economic Environment}

Following the literature, inflation and unemployment are related by an expectations-augmented Phillips curve:

$$
u_{t}=u_{t}^{n}-\lambda\left(\pi_{t}-\pi_{t}^{e}\right)+\eta_{t}, \quad \lambda>0,
$$

where $u_{t}, u_{t}^{n}$, and $\pi_{t}$ are (respectively) the rates of unemployment, natural unemployment and inflation; $\pi_{t}^{e}$ is the public's forecast of inflation at time $t$ constructed at time $t-1$; and $\eta_{t}$ is an aggregate supply disturbance. The public constructs its forecasts rationally:

$$
\pi_{t}^{e}=E_{t-1} \pi_{t}
$$

where $E_{t-1}$ is the expectation conditional on all information available at time $t-1$. The public's information set at time $t-1$ is denoted by $I_{t-1}$ and includes the model parameters and observations of the variables up to and including period $t-1$.

The natural rate of unemployment evolves over time according to

$$
\Delta u_{t}^{n}=\psi+\theta_{1} \Delta u_{t-1}^{n}+\cdots+\theta_{q} \Delta u_{t-q}^{n}+\zeta_{t},
$$

where $\zeta_{t}$ denotes the unpredictable component of the natural rate and all roots of the polyno-

mial $1-\sum_{i=1}^{q} \theta_{i} L^{i}$ are assumed to lay outside the unit circle. This autoregressive model for the natural rate represents the idea that changes in technology, labor force demographics, and minimum wage rates (among others) can affect the labor market and generate movements in the natural rate. For example, Shimer (1998) argues that in the absence of the baby boom, the US rate of unemployment would have neither increased in the 1960's and 1970's, nor fallen afterwards.

The central banker affects the rate of inflation by means of a policy instrument. We can interpret this instrument as a monetary aggregate or a short-term interest rate. The instrument is imperfect in the sense that in a stochastic world, it cannot determine inflation completely:

$$
\pi_{t}=i_{t}+\epsilon_{t}
$$

where $i_{t}$ is the policy instrument and $\epsilon_{t}$ is a control error that represents imperfections in the conduct of monetary policy. Since $i_{t}$ is chosen at time $t-1, i_{t} \in I_{t-1}$. This simple specification relaxes the assumption that the monetary authority chooses directly the rate of inflation after observing (before the public does) the random shocks. Instead, the central banker here has no informational advantage over the public since neither of them observe at time $t-1$ the realization of the disturbances at time $t$. As noted by Cukierman (2000), the central banker's uncertainty regarding next period's realizations of inflation and unemployment is crucial in generating an inflation bias when preferences are asymmetric.

Finally, the structural disturbances of the model $\left(\eta_{t}, \zeta_{t}\right.$, and $\left.\epsilon_{t}\right)$ are serially uncorrelated, jointly normally distributed with zero mean, and possibly conditionally heteroskedastic. The assumption of normality is essential to obtain a closed-form analytical solution. The assumption of conditional heteroskedasticity allows changes over time in the volatility of 
the structural shocks. For example, the net change in nominal oil prices, that could be assimilated to a supply shock, appears to have been more variable in the 1970's than in the 1960's or the 1980's [see Hamilton (1996, figure 2)].

\subsection{The Central Banker}

The central banker's preferences over inflation and unemployment are represented by the loss function:

$$
L\left(\pi_{t}, u_{t}\right)=(1 / 2)\left(\pi_{t}-\pi_{t}^{*}\right)^{2}+\left(\phi / \gamma^{2}\right)\left(\exp \left(\gamma\left(u_{t}-u_{t}^{*}\right)\right)-\gamma\left(u_{t}-u_{t}^{*}\right)-1\right),
$$

where $\pi_{t}^{*}$ and $u_{t}^{*}$ denote the targeted rates of inflation and unemployment, respectively; $\phi$ is a positive coefficient; and $\gamma$ is a nonzero real number. The targeted unemployment rate is the expected natural rate of unemployment:

$$
u_{t}^{*}=E_{t-1} u_{t}^{n} .
$$

The possibly nonzero rate of inflation $\pi_{t}^{*}$ can be interpreted as the one implied by Friedman's rule or as the one associated with the optimal inflation tax. It is assumed that $\pi_{t}^{*}$ is stable enough to be well approximated by a constant term (denoted by $\pi^{*}$ below). Section 4 discusses the implications of this assumption.

In contrast to most of the preceding literature where both components of the central banker's loss function are quadratic, the unemployment component in (5) is described by the linex function $g(x)=[\exp (\alpha x)-\alpha x-1] / \alpha^{2}$ [Varian (1974)]. To my knowledge, the first paper to employ this loss function in monetary policy games was Nobay and Peel (1998). In order to develop some intuition, the linex function is plotted in figure 1 for the special case where $\gamma>0$. For unemployment rates above $u_{t}^{*}$, the exponential term eventually dominates and the loss associated with a positive deviation rises exponentially. For unemployment rates below $u_{t}^{*}$, it is the linear term that becomes progressively more important as unemployment decreases and, consequently, the loss rises linearly. This asymmetry can be seen in figure 1 by considering, as an example, the loss associated with a \pm 1 unemployment deviation from $u_{t}^{*}$. Even though their magnitudes are the same, the -1 deviation delivers a smaller loss than the +1 deviation. Thus, positive unemployment deviations are weighted more severely than negative ones in the central banker's loss function. The converse is true when $\gamma<0$.

The linex function is attractive for several reasons. First, it is analytically tractable and yields a closed-form solution when shocks are normally distributed. Second, it generates testable empirical predictions (see below). Finally, it nests the usual quadratic loss function as a special case when the preference parameter $\gamma$ tends to zero. ${ }^{1}$ This result suggests that the hypothesis of quadratic preferences over unemployment could be tested empirically by evaluating whether $\gamma$ is significantly different from zero. In principle, one could extend (5)

\footnotetext{
${ }^{1}$ Formally,

$$
\operatorname{Lim}_{\gamma \rightarrow 0} \frac{\exp (\gamma x)-\gamma x-1}{\gamma^{2}}=\operatorname{Lim}_{\gamma \rightarrow 0} \frac{x \exp (\gamma x)-x}{2 \gamma}=\operatorname{Lim}_{\gamma \rightarrow 0} \frac{x^{2} \exp (\gamma x)}{2}=\frac{x^{2}}{2} .
$$
}


to allow asymmetries regarding the inflation rate. This possibility is discussed in section 3, where it is argued that the basic predictions of the model are robust to this extension.

The asymmetric loss function means to represent the idea that policy makers have different attitudes vis a vis expansions and recessions. In general, both positive and negative deviations from the natural rate are deemed costly, but under (5), the sign of the deviation is important for the central banker. In the plausible case where $\gamma>0$, expansions are preferred to recessions. In the empirical literature, Dolado et al. (2000) and Gerlach (2000) find that the US Federal Reserve reacts more strongly, in terms of changes to the Federal Funds rate, to negative than positive output gaps. Cukierman (2000) considers an asymmetric loss function where the loss is quadratic when unemployment is above the natural rate and zero when unemployment is below. Cukierman's specification is appealing because it seems likely that, given inflation, unemployment rates below the natural yield negligible costs (and possibly benefits) to the monetary authority. In contrast, the linex and quadratic loss functions assume a strictly positive cost when unemployment is below the natural rate. As noted by Cukierman (p. 9), the finding of an inflation bias when the unemployment target is the natural rate depends on the assumption that the central banker is more concerned about too much that too little unemployment. His finding and the one of this paper suggest that this result is robust to the precise functional form of the central banker's loss function, provided this asymmetry is preserved.

\subsection{Nash Equilibrium}

The central banker's problem is to choose the sequence of instruments that minimizes the present discounted value of her loss function:

$$
\underset{\left\{i_{t+s}\right\}_{s=0}^{\infty}}{\operatorname{Min}} E_{t-1} \sum_{s=0}^{\infty} \beta^{s} L\left(\pi_{t+s}, u_{t+s}\right)
$$

where $\beta \in(0,1)$ is the discount rate and the public's inflation forecasts are taken as given. Since the natural unemployment rate is assumed to be determined by factors beyond the scope of monetary policy, the instrument does not affect the path of $u_{t}^{n}$ and the central banker's objective function can be decomposed into a sequence of one-period problems. This decomposition simplifies the solution of the model and, as it will be shown below, delivers a unique subgame-perfect Nash equilibrium. The first-order condition is

$$
\left.E_{t-1} \pi_{t}-\pi^{*}-(\lambda \phi / \gamma)\left(\exp \left(-\lambda \gamma\left(E_{t-1} \pi_{t}-\pi_{t}^{e}\right)+\gamma^{2} \sigma_{u, t}^{2} / 2\right)\right)-1\right)=0,
$$

where $\sigma_{u, t}^{2}$ represents the conditional variance of unemployment. Since the linex loss function is globally convex, the second-order sufficient condition for a minimum is satisfied. In writing (7), I have used the fact that when shocks are normal, the distribution of unemployment conditional on $I_{t-1}$ is normal. Hence, the distribution of $\exp \left(\gamma\left(u_{t}-E_{t-1} u_{t}^{n}\right)\right)$ is $\log$ normal with conditional mean $\left.\exp \left(-\lambda \gamma\left(E_{t-1} \pi_{t}-\pi_{t}^{e}\right)+\gamma^{2} \sigma_{u, t}^{2} / 2\right)\right) .^{2}$

\footnotetext{
${ }^{2}$ See the working paper version of this article [Ruge-Murcia (2000)] for detailed derivation and proofs.
} 
Equation (7) defines implicitly the central banker's reaction (or best move) for any given inflation forecast by the public: ${ }^{3}$

$$
\begin{aligned}
& h\left(E_{t-1} \pi_{t}, \pi_{t}^{e}\right) \\
& \left.\quad=E_{t-1} \pi_{t}-\pi^{*}-(\lambda \phi / \gamma)\left(\exp \left(-\lambda \gamma\left(E_{t-1} \pi_{t}-\pi_{t}^{e}\right)+\gamma^{2} \sigma_{u, t}^{2} / 2\right)\right)-1\right)=0
\end{aligned}
$$

Using the implicit function theorem, it is possible to show that $0<\partial E_{t-1} \pi_{t} / \partial \pi_{t}^{e}<1$ for all $\gamma$, and that $\partial^{2} E_{t-1} \pi_{t} / \partial\left(\pi_{t}^{e}\right)^{2}$ is larger than zero for $\gamma>0$, equal to zero for $\gamma \rightarrow 0$, and less than zero for $\gamma<0$. In other words, the central banker's reaction function is monotonically increasing in $\pi_{t}^{e}$ but can be convex, linear, or concave depending on the sign of $\gamma$.

In order to develop some intuition, Figure 2 plots the central banker's reaction function for two different values of the preference parameter $\gamma$. The figure also includes the reaction functions of the public and of a central banker with quadratic preferences. The former is summarized by the rational expectations relation (2). The latter is obtained from (8) by taking the limit $\gamma \rightarrow 0$ and solving explicitly. The graphs are constructed assuming an optimal rate of inflation $\pi^{*}=0$. Treating all parameters as fixed, the central banker's reaction is computed by solving numerically the implicit function (8) for different values of $\pi_{t}^{e}$. The Nash equilibrium is the point where (8) and (2) intersect. In all cases the central banker's reaction is an increasing function of the public's inflation forecast. However, her willingness to accommodate agents' expectations varies with the preference parameter $\gamma$. For the quadratic central banker, the Nash equilibrium corresponds to $\pi=0$, that is the optimal inflation rate. Hence, the inflation bias is zero. On the other hand, for $\gamma>0,(\gamma<0)$, an inflation (deflation) bias can arise, even if the unemployment target is the natural rate.

Conditions for the existence and uniqueness of the Nash equilibrium are given in the following proposition:

Proposition 1. Provided $\gamma \neq 0$, there exists a unique $\pi_{t}^{e}=E_{t-1} \pi_{t}$, such that $h\left(E_{t-1} \pi_{t}, \pi_{t}^{e}\right)=$ 0 .

Proof. To prove existence, construct

$$
\pi_{t}^{e}=E_{t-1} \pi_{t}=\pi^{*}+(\lambda \phi / \gamma)\left(\exp \left(\gamma^{2} \sigma_{u, t}^{2} / 2\right)-1\right) .
$$

Plugging (9) into (8) and using $\pi_{t}^{e}=E_{t-1} \pi_{t}$ delivers $h\left(E_{t-1} \pi_{t}, \pi_{t}^{e}\right)=0$. To show uniqueness, assume there exists a second inflation forecast, say $\hat{\pi}_{t}^{e}=\pi^{*}+(\lambda \phi / \gamma)\left(\exp \left(\gamma^{2} \sigma_{u, t}^{2} / 2\right)-1\right)+$ $x$, that also lies on the $45^{\circ}$ line on the plane $\left(\pi_{t}^{e}, E_{t-1} \pi_{t}\right)$ and satisfies $h\left(E_{t-1} \pi_{t}, \pi_{t}^{e}\right)=0$. Replacing $\hat{\pi}_{t}^{e}$ in (8), makes clear that the only way $h\left(E_{t-1} \pi_{t}, \pi_{t}^{e}\right)=0$ is if $x=0$. $\uparrow$

\subsection{The Inflation Bias}

The inflation bias is the systematic difference between equilibrium and optimal inflation. When a central banker with asymmetric preferences targets the natural rate, the bias is:

$$
(\lambda \phi / \gamma)\left(\exp \left(\gamma^{2} \sigma_{u, t}^{2} / 2\right)-1\right)
$$

\footnotetext{
${ }^{3}$ Strictly speaking, the reaction function relates the policy instrument, $i_{t}$, to $\pi_{t}^{e}$, both of which are determined at time $t-1$. However, in what follows it will be convenient to work with $E_{t-1} \pi_{t}$ rather than $i_{t}$. Since these two variables are monotonically related, this approach entails no loss of generality.
} 
For the special case where preferences are quadratic, the bias can be computed by taking

$$
\operatorname{Lim}_{\gamma \rightarrow 0}(\lambda \phi / \gamma)\left(\exp \left(\gamma^{2} \sigma_{u, t}^{2} / 2\right)-1\right)=0
$$

Since the inflation bias is zero, monetary policy is not temporally inconsistent under discretion. ${ }^{4}$ Hence, the theory cannot explain suboptimally high rates of inflation as the result of the lack of a commitment technology.

Clearly, the finding that the inflation bias is zero when the central banker targets the natural rate is not robust to relaxing the assumption of quadratic preferences. In the more general case where the central banker's preferences are asymmetric, the inflation bias is different from zero. This result follows from the observation that $\lambda \phi\left(\exp \left(\gamma^{2} \sigma_{u, t}^{2} / 2\right)-1\right)$ is always positive and $\gamma \neq 0$, by assumption. The sign of the bias depends on whether $\gamma \lessgtr 0$. In the case where $\gamma<0$, there is a deflation bias. More plausibly, in the case where $\gamma>0$, there is an inflation bias. Recall that $\gamma>0$ means that the central banker attaches a larger loss to positive than negative unemployment deviations from the natural rate.

The bias is proportional to the conditional variance of unemployment. To understand why, recall that when the loss function is quadratic, certainty equivalence holds. The solution of the model is the same regardless of whether there is uncertainty or not, and only the first (conditional) moment of unemployment explains the rate of inflation. On the other hand, with asymmetric unemployment preferences, the marginal benefit of surprise inflation is not linear in unemployment, but convex (when $\gamma>0$ ) or concave (when $\gamma<0$ ). When $\gamma>0$, an increase in uncertainty raises the expected marginal benefit of surprise inflation. ${ }^{5}$

This paper relaxes the usual linear-quadratic framework in a particular dimension. That is, it relaxes the assumption of a quadratic objective function but preserves the linear constraint (the expectations-augmented Phillips curve). Alternatively, one could consider a model where the objective function is quadratic but the supply function is nonlinear. This is the strategy followed by Nobay and Peel (2000). These authors show analytically that the nonlinearity of the supply schedule yields ambiguous implications for the inflation bias. Nonetheless, there exist parameter values for which a nonlinear Phillips curve could produce an inflation bias.

For given values of $\phi$ and $\lambda$, and $\gamma>0$, the model predicts a positive relation between inflation and the conditional variance of unemployment. Consider first the special case where the conditional variance of unemployment is constant. That is, $\sigma_{u, t}^{2}=\sigma_{u}^{2}$ for all $t$. Then, the inflation bias is also (a positive) constant. Because the bias cannot be identified separately from $\pi^{*}$, it is not possible to test the positive relation between $\sigma_{u}^{2}$ and $\pi_{t}$ in the time series dimension. However, this hypothesis could be examined using cross section data on $\sigma_{u}^{2}$ and average inflation. Since the unemployment disturbance has the supply shock as

\footnotetext{
${ }^{4}$ This result is immediate if one considers the case $k=1$ in equation (9) in Barro and Gordon (1983, p. 597 ), where $k$ is the fraction of the natural rate that is targeted by the central banker.

${ }^{5}$ There exists a comparable result in the consumption literature. When one relaxes the assumption of quadratic utility and labor income risk in nondiversifiable, uncertainty increases the expected marginal utility of future consumption. To satisfy the Euler condition, agents decrease current consumption compared to future consumption and increase savings. Individuals in occupations with more variable income (e.g, farmers) would have above-average savings rates [see Skinner (1988)].
} 
one its components, the model also predicts a positive association between the variance of supply shocks and the rate of inflation. Evidence supporting this implication is provided by Gerlach (1999) using a cross section of industrial economies.

Consider now the case where the conditional variance of unemployment changes over time. Then, the model predicts that periods of more volatile unemployment should be associated with higher rates of price inflation. This hypothesis is examined below using time series data from G7 countries.

\section{Empirical Analysis}

The empirical analysis of the game-theoretical developed above is nontrivial for several reasons. First, the natural rate of unemployment is not directly observable. Hence, in order to estimate the model using data on inflation and unemployment alone, it is necessary to construct a reduced-form version of the model. Second, the conditional variance of the rate of unemployment is not directly observable either. It is possible to construct an estimate of $\sigma_{u, t}^{2}$ on the basis of a fully parametric model like the ARCH or GARCH specifications of Engle (1982) and Bollerslev (1986). However since $\sigma_{u, t}^{2}$ is then a generated regressor, one must consider its effect on the efficiency and consistency of the estimates. Finally, it is not possible to recover all structural parameters of the model from the reduced-form estimates. In particular, the preference parameter $\gamma$ is not identified. However, we will see below that the sign of the reduced-form coefficient on $\sigma_{u, t}^{2}$ is informative about the sign of $\gamma$.

The working paper version of this article [Ruge-Murcia (2000)] shows that when the natural rate of unemployment follows the $\operatorname{AR}(q)$ process in (3) and the structural shocks are mutually uncorrelated at all leads and lags, the first-difference of unemployment can be written in reduced-form as an unrestricted $\operatorname{ARMA}(q, q+1)$ process. Regarding the inflation rate, one can use equations (9) and (4) to write

$$
\pi_{t}=\pi^{*}+(\lambda \phi / \gamma)\left(\exp \left(\gamma^{2} \sigma_{u, t}^{2} / 2\right)-1\right)+\epsilon_{t}
$$

Notice, however, that it is not possible to identify separately the parameters $\pi^{*}, \lambda, \phi$ and $\gamma$. To see this, rewrite the above equation as $\pi_{t}=\left(\pi^{*}-\lambda \phi / \gamma\right)+(\lambda \phi / \gamma) \exp \left(\gamma^{2} \sigma_{u, t}^{2} / 2\right)+\epsilon_{t}$. An estimate of the intercept term would only deliver the linear combination $\pi^{*}-\lambda \phi / \gamma$, and

the time-series variation of $\sigma_{u, t}^{2}$ alone would not identify $\lambda, \phi$ and $\gamma$. A transformation of the model that confronts directly the lack of identification involves the linearization of the exponential term in (11) by means of a first-order Taylor series expansion. Then, inflation can be written in reduced-form as:

$$
\pi_{t}=a+b \sigma_{u, t}^{2}+\epsilon_{t}
$$

where $a$ is a constant intercept and $b=\lambda \phi \gamma$. Although an estimate of $b$ cannot reveal the values of $\lambda, \phi$, and $\gamma$, its sign is informative regarding the asymmetry in the central banker's preferences. Since $\lambda, \phi>0$, a positive estimate of $b$ implies $\gamma>0$ and would be consistent with the idea that the central banker weights more heavily positive than negative 
unemployment deviations from the natural rate. ${ }^{6}$

The data set consists of quarterly seasonally adjusted observations of inflation and unemployment for Canada, France, Italy, Japan, United Kingdom, and the United States. ${ }^{7}$ The inflation rate is measured by the percentage change (on an annual basis) in the GDP deflator. The unemployment rate is measured by the average rate of civilian unemployment in the three months of the quarter. The raw quarterly GDP deflator and the monthly unemployment rate were taken from OEDC Main Economic Indicators. The sample period was determined by the first and latest available observation of both variables in the data base. That is, 1961:1 to 1999:2 for Canada, 1970:1 to 1999:2 for France and Italy, and 1960:1 to 1999:2 for Japan, the United Kingdom and the United States.

Prior to the estimation of the model, econometric tests were employed to examine the time-series properties of the rate of unemployment. Table 1 (panel A) reports the results of Augmented Dickey-Fuller (ADF) and Phillips-Perron (PP) unit-root tests. In all cases, the null hypothesis of a unit root in unemployment cannot be rejected at the $5 \%$ level, though the ADF test would reject the hypothesis for unemployment at the $10 \%$ level for the United States. Similar results are reported, for example, by Broadbent and Barro (1997) and Ireland (1999) and underpin the modeling of unemployment as an $I(1)$ variable. $^{8}$

The model with asymmetric preferences predicts a relation between the conditional variance of unemployment and the inflation rate. It is possible to examine this association in a time series dimension only if unemployment is conditionally heteroskedastic (that is, if $\sigma_{u, t}^{2}$ changes over time). Otherwise, if $\sigma_{u, t}^{2}$ is constant, its coefficient $b$ is not identified. Hence, before proceeding further, it is important to test whether the conditional variance of unemployment is indeed time-varying. Table 1 (panel B) reports the results of Lagrange Multiplier (LM) tests for neglected ARCH. For Canada, the United Kingdom and the United States, the hypothesis of no conditional heteroskedasticity can be rejected at the $1 \%$ significance level. Similarly, for France, the hypothesis can be rejected at the $10 \%$ or $5 \%$ levels depending on the number of lags used to compute the statistic. Results for Italy are more ambiguous in that the hypothesis can be rejected at the $10 \%$ when two lags are included in the regression but it cannot be rejected in the remaining cases. However, since the $p$-values are only $0.13,0.11$, and 0.16 when using 1,3 , and 4 lags, respectively, these conclusions appear to be marginal. Finally, for Japan the hypothesis cannot be rejected regardless of the number of lags in the test regression. In summary, test results indicate that the conditional variance of unemployment changes over time in Canada, France, the United Kingdom, and

\footnotetext{
${ }^{6}$ When preferences are asymmetric on both inflation and unemployment, the model solution differs from (11) in the intercept term and the functional form relating $\pi_{t}$ and $\sigma_{u, t}^{2}$. However, since the linearized version of the model is the same, it would appear that this generalization does not alter fundamentally the model predictions. In principle, one could consider additional regressors (e.g., lagged inflation) in (12). However, since the model predicts that inflation depends primarily on the conditional variance of unemployment, I have abstained from including extra regressors and adopted the reduced-form specification that is closest to the theoretical model.

${ }^{7}$ I also considered including Germany in the sample. Unfortunately, its series are incomplete or unavailable in the data base and reunification makes hard to compare data before and after 1990.

${ }^{8}$ Since unit-root tests have low power against persistent, but stationary, specifications, I also estimated the model under the assumption that unemployment is stationary in levels. Results were very similar to the ones reported and are available from the author upon request.
} 
the United States. There is milder (no) evidence of conditional heteroskedasticity in the case of Italy (Japan). In light of these results, the time series analysis that follows is carried out using data for Canada, France, Italy, the United Kingdom, and the United States.

The model is estimated by the numerical maximization of the joint log likelihood function of inflation and unemployment. ${ }^{9}$ The asymptotic variance-covariance matrix is estimated by the inverse of the Hessian of the log likelihood function at the maximum. Since any stationary ARMA process can be approximated arbitrarily well by a finite autoregression, and the estimation of ARMA processes is frequently complicated by common factors, $\Delta u_{t}$ is estimated in autoregressive form. ${ }^{10}$ The lag length of the AR representation was determined using a sequence of Likelihood Ratio (LR) tests. The conditional variance of the rate of unemployment is parameterized using a $\operatorname{GARCH}(1,1)$ model. An advantage of this parameterization is that it can capture the persistence of the conditional variance in a more parsimonious manner than higher-order ARCH processes. Recall that the Barro-Gordon model predicts a linear relationship between inflation and current unemployment. In contrast, under a GARCH specification for $\sigma_{u, t}^{2}$, this model predicts a nonlinear relationship between inflation and lagged unemployment.

ML estimates of the processes of inflation, unemployment, and the conditional variance of unemployment are reported in table 2. The coefficient of the conditional variance of unemployment is positive in all cases and, for France and the United States, it is statistically significant. For these two countries the null hypothesis $b=0$ can be rejected at the $1 \%$ and 5\% significance levels, respectively. Recall that because $b=\lambda \phi \gamma$, the value of $\hat{b}$ is uninformative about the magnitude of the parameter that measures the asymmetry in the central banker's preferences, $\gamma$. However, since $\lambda, \phi>0$, a positive $\hat{b}$ implies $\gamma>0$. Hence, positive deviations from the natural unemployment rate appear to be weighted more heavily than negative ones in the central banker's loss function. This result could explain the empirical finding by Dolado et al. (2000) and Gerlach (2000) whereby the US Federal Reserve reacts more strongly to negative than positive output gaps.

For Canada, Italy, and the United Kingdom, $\hat{b}$ is positive but its standard error is large enough that one would not reject the hypothesis that the slope coefficient equals zero. This result is compatible with the standard model where the loss function is quadratic and the conditional variance of unemployment has no explanatory power over the rate of inflation. Hence, for these countries, departures from quadratic unemployment preferences appear to be small or perhaps not of the functional form explored here.

The countries for which $b$ is statistically different from zero, are also the countries for which the conditional variance of unemployment is the most persistent. Figure 3 plots the impulse response associated with a 1 standard-deviation innovation to $\sigma_{u, t}^{2}$. Notice that for Canada, Italy, and the United Kingdom, the effect of the innovation on the conditional variance is not very persistent. After 2 quarters, the effect is half or less than half the

\footnotetext{
${ }^{9}$ An alternative estimation strategy involves computing $\sigma_{u, t}^{2}$ using the unemployment series and then running an OLS regression of $\pi_{t}$ on $\sigma_{u, t}^{2}$. This strategy yields less efficient estimates than Maximum Likelihood because it does not impose the cross-equation restrictions of the model and does not exploit the contemporaneous correlation of the reduced form disturbances. Results using OLS yield the same conclusions as those based on ML and are available from the author upon request.

${ }^{10}$ Results using a low-order $A R M A$ process yielded virtually the same results as reported below. These results are available from the author upon request.
} 
initial shock. On the other hand, for France and the United States, innovations to $\sigma_{u, t}^{2}$ are much more persistent. After 8 quarters (2 years) the effect is still 0.55 and 0.37 of the initial shock, respectively. This result provides another interpretation for the finding that $b$ is not statistically significant in the case of Canada, Italy, and the United Kingdom: the time-variation in the conditional variance of unemployment is of too short duration to account for the inflation persistence in these countries.

Since the conditional variance is estimated using unemployment data, $\sigma_{u, t}^{2}$ is a generated regressor. Pagan (1984) and Pagan and Ullah (1988) examine the implications of generated regressors in estimation and inference. In most cases, generated regressors can be problematic because they measure with noise the true, but unobserved, regressor. In the specific case where the conditional variance is computed using an ARCH-type model, the ML estimator is likely to be biased and inconsistent if the model for $\sigma_{u, t}^{2}$ is misspecified. Unfortunately, the instrumental variable estimator proposed by Pagan and Ullah cannot be employed in this case because the current endogenous variable is a function of all past history and no instruments are available. Instead, Pagan and Ullah (p. 99) suggest specification tests to assess whether the chosen $\mathrm{ARCH}$ model is valid. A standard misspecification test for ARCH models is the Ljung-Box Q-statistic applied to the standardized residuals squared. If the ARCH model is correctly specified, then the residuals corrected for heteroskedasticity and squared should be serially uncorrelated. Table 3 reports the Q-statistic for up to six autocorrelations for all countries. Since all statistics are below the $5 \%$ critical value of the appropriate distribution, the null hypothesis of no autocorrelation cannot be rejected at the $5 \%$ level. Hence, it would appear that the parsimonious $\operatorname{GARCH}(1,1)$ model employed here adequately captures the conditional heteroskedasticity present in the unemployment data.

\section{Summary and Discussion}

This paper examines, both analytically and empirically, the notion that an inflation bias can arise in a setup where a central banker with asymmetric preferences targets the natural unemployment rate. Using a model where the natural rate varies over time and a preference specification that includes the quadric loss function as a special case, it shows that the basic insight in Kydland and Prescott (1977) and Barro and Gordon (1983) is robust to allowing the monetary authority to target the natural rate. A basic time-series prediction of the model is that inflation and the conditional variance of unemployment are positively related. Maximum Likelihood estimates of the reduced-form parameters support this hypothesis for the United States and France, but not for Canada, Italy, or the United Kingdom. Although the preference parameter that measures the asymmetry in unemployment preferences is not identified, results are consistent with the view that positive unemployment deviations from the target are weighted more severely than negative ones in the central banker's loss function.

In interpreting these empirical results, one must keep in mind some limitations of the game-theoretical model. First, preference parameters (including the inflation target $\pi^{*}$ ) could change over time as different individuals take office, and institutional arrangements are revised. For example, it is possible that the reduction in the inflation rate in the 1990's is not only due to the smaller variability of the unemployment rate but also to institutional changes like the introduction of explicit inflation targets. Second, the unemployment per- 
sistence is only due to the persistence in the natural rate. A more general model would allow, for example, hysteresis in unemployment or an explicit role for technological or business cycle variables. Lockwood and Philippopoulos (1994) consider a model where lagged unemployment affects the current natural rate. Unfortunately, when coupled with the more general preference specification employed here, the model has no closed-form solution. Finally, although the model allows for the strategic interaction of the public and the central banker, equilibrium concepts other than Nash might be empirically important. Future work seeks to address this limitations, but the results reported above are suggestive of the role of asymmetric preferences in real-world monetary policy making. 


\section{Table 1. Univariate Analysis of the Unemployment Rate}

\begin{tabular}{ccccccc}
\hline \hline & \multicolumn{6}{c}{ Country } \\
\cline { 2 - 7 } & Canada & France & Italy & Japan & UK & USA \\
\hline \multicolumn{7}{c}{ A. Unit Root Tests } \\
ADF & -1.68 & -1.40 & -1.04 & 0.62 & -1.83 & $-2.88^{\dagger}$ \\
PP & -1.48 & -1.45 & -1.34 & -2.09 & -1.37 & -2.09 \\
\multicolumn{7}{c}{ B. LM Tests for Neglected ARCH } \\
1 lag & $9.11^{* *}$ & $3.90^{*}$ & 2.26 & 0.01 & $13.85^{* *}$ & $11.70^{* *}$ \\
2 lags & $11.96^{* *}$ & $7.25^{*}$ & $5.31^{\dagger}$ & 1.15 & $14.07^{* *}$ & $16.51^{* *}$ \\
3 lags & $12.41^{* *}$ & $7.61^{\dagger}$ & 6.02 & 1.23 & $14.69^{* *}$ & $16.50^{* *}$ \\
4 lags & $13.34^{* *}$ & $8.28^{\dagger}$ & 6.55 & 1.19 & $14.63^{* *}$ & $16.47^{* *}$ \\
& \multicolumn{7}{c}{} \\
\hline
\end{tabular}

Notes: ADF and PP stand for Augmented Dickey-Fuller and Phillips-Perron, respectively. The LM statistics were calculated as the product of the number of observations and the uncentered $R^{2}$ of the OLS regression of the squared unemployment residual on a constant and one, two, three and four of its lags. Under the null hypothesis of no conditional heteroskedasticity, the statistic is distributed chi-square with as many degrees of freedom as squared residuals are included in the regression. The superscripts ${ }^{* *},{ }^{*}$, and ${ }^{\dagger}$ denote the rejection of the null hypothesis at the $1 \%, 5 \%$ and $10 \%$ significance levels, respectively. 
Table 2. ML Estimates

\begin{tabular}{|c|c|c|c|c|c|}
\hline \multirow[t]{2}{*}{$\overline{\text { Parameter }}$} & \multicolumn{5}{|c|}{ Country } \\
\hline & Canada & France & Italy & UK & $\overline{\mathrm{USA}}$ \\
\hline \multicolumn{6}{|c|}{ A. Inflation Process } \\
\hline$a$ & $\begin{array}{l}4.08^{* *} \\
(0.60)\end{array}$ & $\begin{array}{l}2.06^{*} \\
(1.03)\end{array}$ & $\begin{array}{l}9.31^{* *} \\
(0.72)\end{array}$ & $\begin{array}{l}6.27^{* *} \\
(0.80)\end{array}$ & $\begin{array}{l}3.08^{* *} \\
(0.40)\end{array}$ \\
\hline$b$ & $\begin{array}{c}5.05 \\
(5.56)\end{array}$ & $\begin{array}{c}111.08^{* *} \\
(36.00)\end{array}$ & $\begin{array}{c}1.60 \\
(4.10)\end{array}$ & $\begin{array}{c}17.79 \\
(28.96)\end{array}$ & $15.38^{*}$ \\
\hline$\sigma_{\epsilon}$ & $\begin{array}{l}3.61^{* *} \\
(0.21)\end{array}$ & $\begin{array}{l}3.60^{* *} \\
(0.25)\end{array}$ & $\begin{array}{l}5.87^{* *} \\
(0.38)\end{array}$ & $\begin{array}{l}5.79^{* *} \\
(0.33)\end{array}$ & $\begin{array}{l}2.34^{* *} \\
(0.14)\end{array}$ \\
\hline \multicolumn{6}{|c|}{ B. Conditional Variance of Unemployment } \\
\hline$\mu$ & $\begin{array}{l}0.04^{* *} \\
(0.01)\end{array}$ & $\begin{array}{l}0.003^{*} \\
(0.001)\end{array}$ & $\begin{array}{l}0.04^{* *} \\
(0.01)\end{array}$ & $\begin{array}{c}0.01^{* *} \\
(0.003)\end{array}$ & $\begin{array}{c}0.01^{* *} \\
(0.003)\end{array}$ \\
\hline$\alpha$ & $\begin{array}{l}0.23^{*} \\
(0.11)\end{array}$ & $\begin{array}{l}0.12^{* *} \\
(0.04)\end{array}$ & $\begin{array}{c}0.38^{\dagger} \\
(0.18)\end{array}$ & $\begin{array}{l}0.32^{*} \\
(0.13)\end{array}$ & $\begin{array}{c}0.23^{*} \\
(0.10)\end{array}$ \\
\hline$\omega$ & $\begin{array}{l}0.38^{* *} \\
(0.14)\end{array}$ & $\begin{array}{l}0.80^{* *} \\
(0.06)\end{array}$ & $\begin{array}{c}0.32 \\
(0.17)\end{array}$ & $\begin{array}{c}0.04 \\
(0.14)\end{array}$ & $\begin{array}{l}0.64^{* *} \\
(0.11)\end{array}$ \\
\hline \multicolumn{6}{|c|}{ C. Unemployment Process } \\
\hline$\psi$ & $\begin{array}{l}-0.03 \\
(0.03)\end{array}$ & $\begin{array}{c}0.01 \\
(0.01)\end{array}$ & $\begin{array}{c}0.06^{*} \\
(0.03)\end{array}$ & $\begin{array}{c}-0.01 \\
(0.01)\end{array}$ & $\begin{array}{c}-0.04^{*} \\
(0.02)\end{array}$ \\
\hline$\theta_{1}$ & $\begin{array}{l}0.49^{* *} \\
(0.09)\end{array}$ & $\begin{array}{l}0.71^{* *} \\
(0.07)\end{array}$ & $\begin{array}{c}-0.04 \\
(0.12)\end{array}$ & $\begin{array}{l}0.83^{* *} \\
(0.04)\end{array}$ & $\begin{array}{l}0.64^{* *} \\
(0.09)\end{array}$ \\
\hline$\theta_{2}$ & & & $\begin{array}{c}0.20^{*} \\
(0.09)\end{array}$ & & $\begin{array}{c}-0.08 \\
(0.09)\end{array}$ \\
\hline$\theta_{3}$ & & & $\begin{array}{c}0.11 \\
(0.08)\end{array}$ & & $\begin{array}{c}0.08 \\
(0.10)\end{array}$ \\
\hline$\theta_{4}$ & & & $\begin{array}{c}-0.23^{*} \\
(0.09)\end{array}$ & & $\begin{array}{c}-0.17^{* *} \\
(0.08)\end{array}$ \\
\hline
\end{tabular}

Notes: The conditional variance of the unemployment follows the $\operatorname{GARCH}(1,1)$ process: $w_{t}=\sqrt{h_{t}} \nu_{t}$, where $w_{t}$ is the unemployment disturbance, $\nu_{t}$ is an i.i.d sequence with unit variance, and $h_{t}=\mu+\alpha w_{t-1}^{2}+\omega h_{t-1}$. See notes to Table 1 . 
Table 3. Q-Statistic for Autocorrelation Standardized Squared Residuals of Unemployment

\begin{tabular}{cccccc}
\hline \hline Autocorrelation & \multicolumn{5}{c}{ Country } \\
\cline { 2 - 6 } & Canada & France & Italy & UK & USA \\
\hline & & & & & \\
1 & 0.00 & 0.02 & 0.00 & 0.68 & 0.09 \\
2 & 0.69 & 0.02 & 1.99 & 0.74 & 0.16 \\
3 & 0.69 & 0.12 & 2.79 & 3.87 & 0.56 \\
4 & 1.07 & 1.24 & 3.10 & 3.93 & 0.61 \\
5 & 1.12 & 1.33 & 3.45 & 7.28 & 2.24 \\
6 & 2.59 & 1.34 & 3.56 & 8.16 & 2.51 \\
& & & & & \\
\hline
\end{tabular}

Notes: under the null hypothesis of no autocorrelation, the Q-statistic is distributed chisquare with degrees of freedom equal to the number of autocorrelations. 


\section{References}

[1] Barro, R. and Gordon, D. (1983), "A Positive Theory of Monetary Policy in a Natural Rate Model," Journal of Political Economy, 91: 589-610.

[2] Blinder, A. S. (1998), Central Banking in Theory and Practice, The MIT Press: Cambridge.

[3] Bollerslev, T. (1986), "Generalized Autoregressive Conditional Heteroskedasticity," Journal of Econometrics, 31: 307-327.

[4] Broadbent, B. and Barro, R. J. (1997), "Central Bank Preferences and Macroeconomic Equilibrium," Journal of Monetary Economics, 39: 17-44.

[5] Clarida, R., Galí, J., and Gertler, M. (1999), "The Science of Monetary Policy: A New Keynesian Perspective," Journal of Economic Literature, 37: 1661-1707.

[6] Cukierman, A. (2000), "The Inflation Bias Result Revisited ," Tel-Aviv University, Mimeo.

[7] Dolado, J. J., María-Dolores, R., and Naveira, M. (2000), "Asymmetries in Monetary Policy Rules," Universidad Carlos III, Mimeo.

[8] Engle, R. F. (1982), "Autoregressive Conditional Heteroskedasticity with Estimates of the Variance of United Kingdom Inflation," Econometrica, 50: 987-1007.

[9] Gerlach, S. (1999), "Supply Shocks, Asymmetric Policy Preferences and Excess Inflation," Bank for International Settlements, Mimeo.

[10] Gerlach, S. (2000), "Asymmetric Policy Reactions and Inflation," Bank for International Settlements, Mimeo.

[11] Hamilton, J. D. (1996), "This is what Happened to the Oil Price-Macroeconomy Relationship," Journal of Monetary Economics, 38: 215-220.

[12] Ireland, P. N. (1999), "Does the Time-Consistency Problem Explain the Behavior of Inflation in the United States?", Journal of Monetary Economics, 44: 279-291.

[13] King, M. (1996), "How Should Central Banks Reduce Inflation: Conceptual Issues" in Achieving Price Stability, Federal Reserve Bank of Kansas City.

[14] Kydland, F. and Prescott, E. (1977), "Rules Rather Than Discretion: The Inconsistency of Optimal Plans," Journal of Political Economy, 85: 473-490.

[15] Lockwood, B. and Philippopoulos, A. (1994), "Insider Power, Unemployment Dynamics and Multiple Inflation Equilibria," Economica, 61: 59-77.

[16] McCallum, B. T. (1995), "Two Fallacies Concerning Central Bank Independence," American Economic Review Papers and Proceedings, 85: 201-211. 
[17] McCallum, B. T. (1997), "Crucial Issues Concerning Central Bank Independence," Journal of Monetary Economics, 39: 99-112.

[18] Nobay, R. A. and Peel, D. A. (1998), "Optimal Monetary Policy in a Model of Asymmetric Central Bank Preferences," London School of Economics, Mimeo.

[19] Nobay, R. A. and Peel, D. A. (2000), "Optimal Monetary Policy with a Nonlinear Phillips Curve," Economics Letters, 67: 159-164.

[20] Pagan, A. (1984), "Econometric Issues in the Analysis of Regressions with Generated Regressors," International Economic Review, 25: 221-247.

[21] Pagan, A. and Ullah, A. (1988), "The Econometric Analysis of Models with Risk Terms," Journal of Applied Econometrics, 3:87-105.

[22] Persson, T. and Tabellini, G. (2000), "Political Economics and Macroeconomic Policy," in Handbook of Macroeconomics, edited by J. Taylor and M. Woodford. North-Holland: Amsterdam.

[23] Ruge-Murcia, F. J. (2000), "The Inflation Bias when the Central Banker Targets the Natural Rate of Unemployment," University of Montreal, Mimeo.

[24] Shimer, R. (1998), "Why is the U.S. UnemploymentRate so Much Lower?," NBER Macroeconomics Annual: 33-49.

[25] Skinner, J. (1988), "Risky Income, Life Cycle Consumption, and Precautionary Savings," Journal of Monetary Economics, 22: 237-255.

[26] Varian, H. (1974), "A Bayesian Approach to Real Estate Assessment," in Studies in Bayesian Economics in Honour of L. J. Savage, edited by S. E. Feinberg and A Zellner. North-Holland: Amsterdam. 
Figure 1: Preferences

(a) Asymmetric Preferences

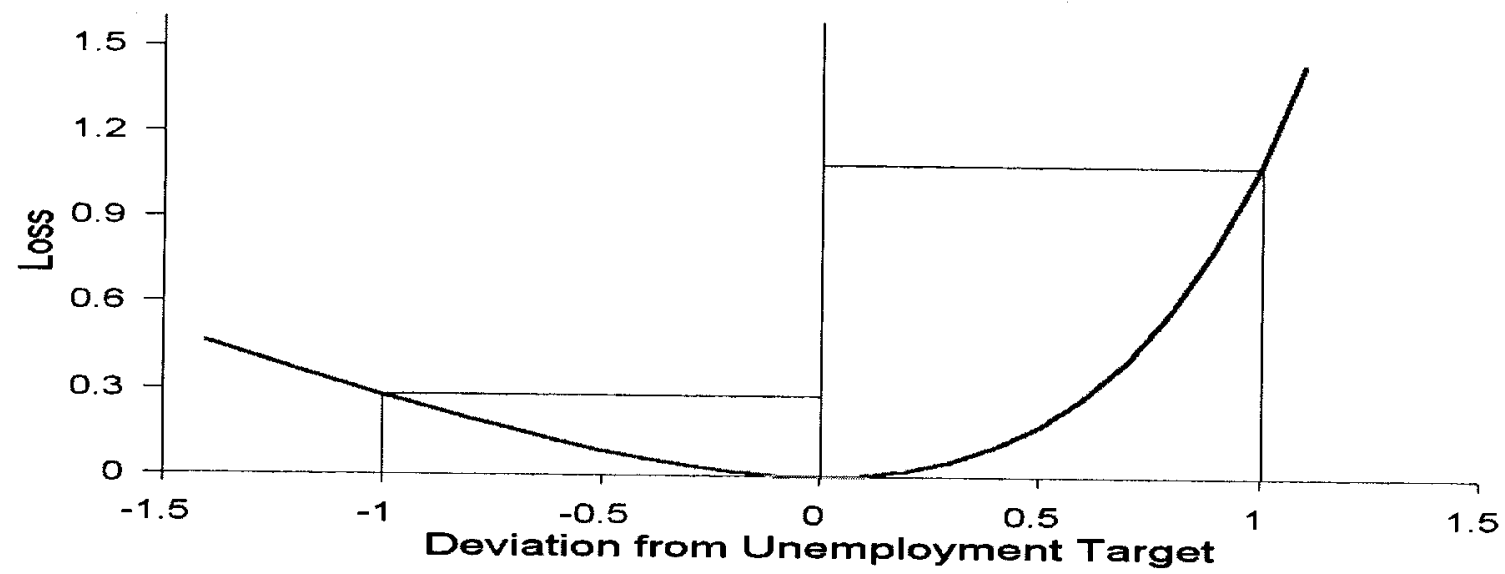

(b) Quadratic Preferences

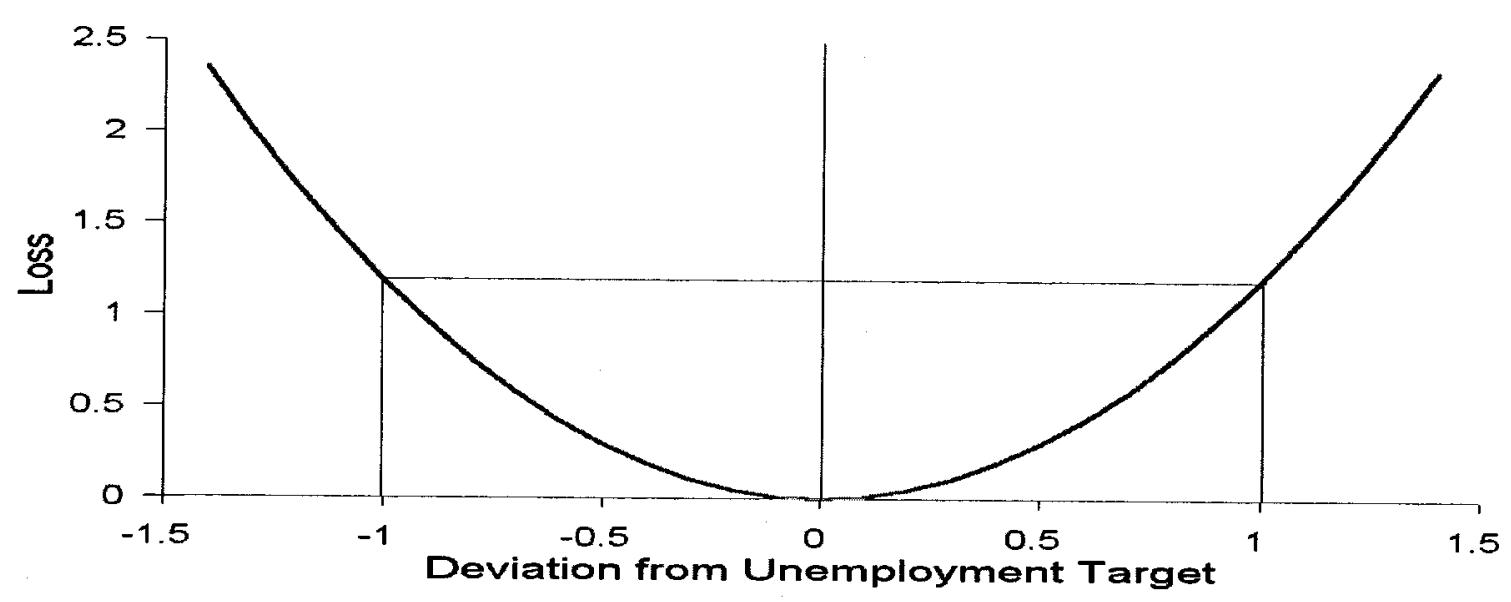


Figure 2: Reaction Functions

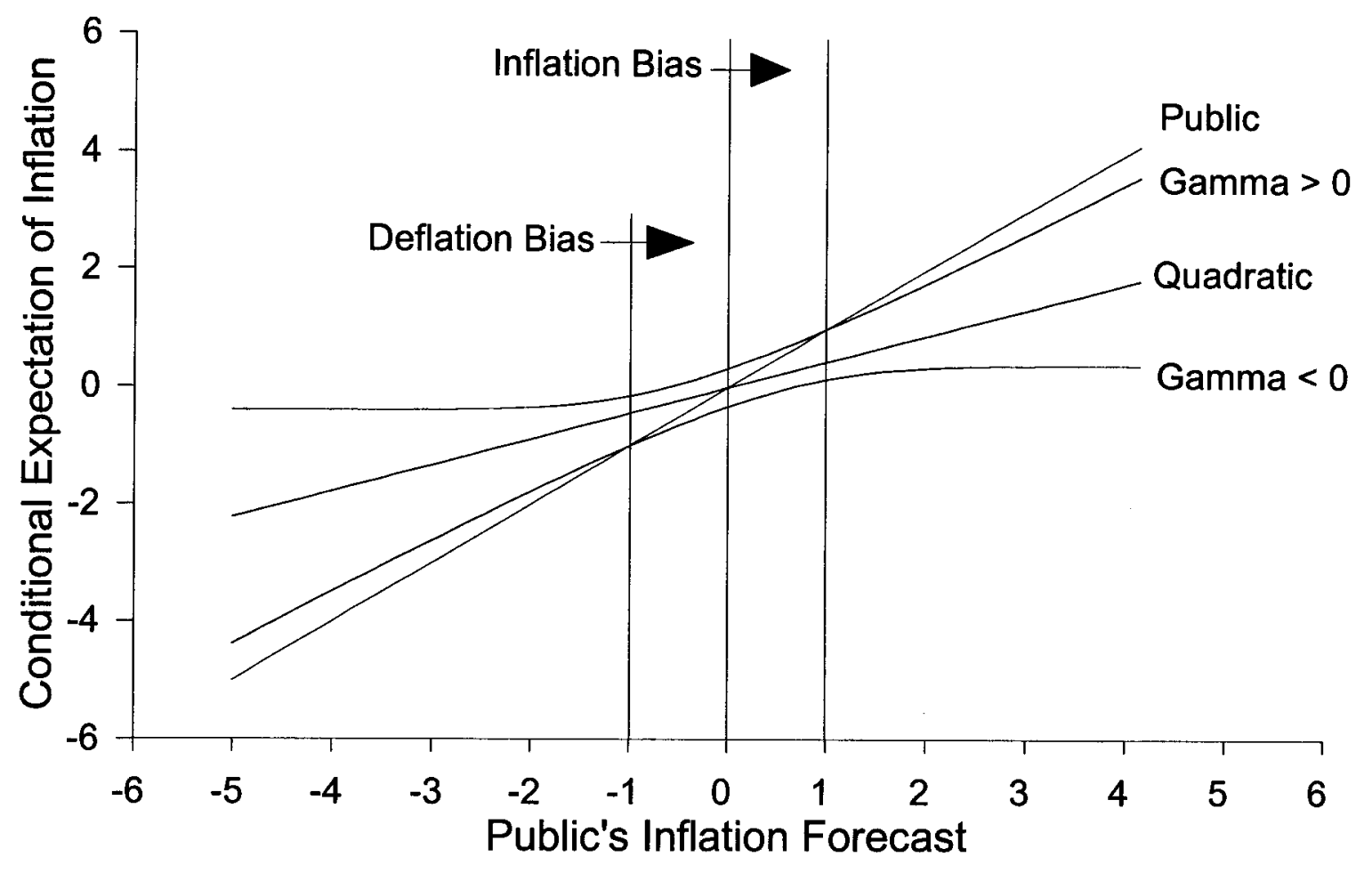


Figure 3: Persistence of the Conditional Variance of Unemployment
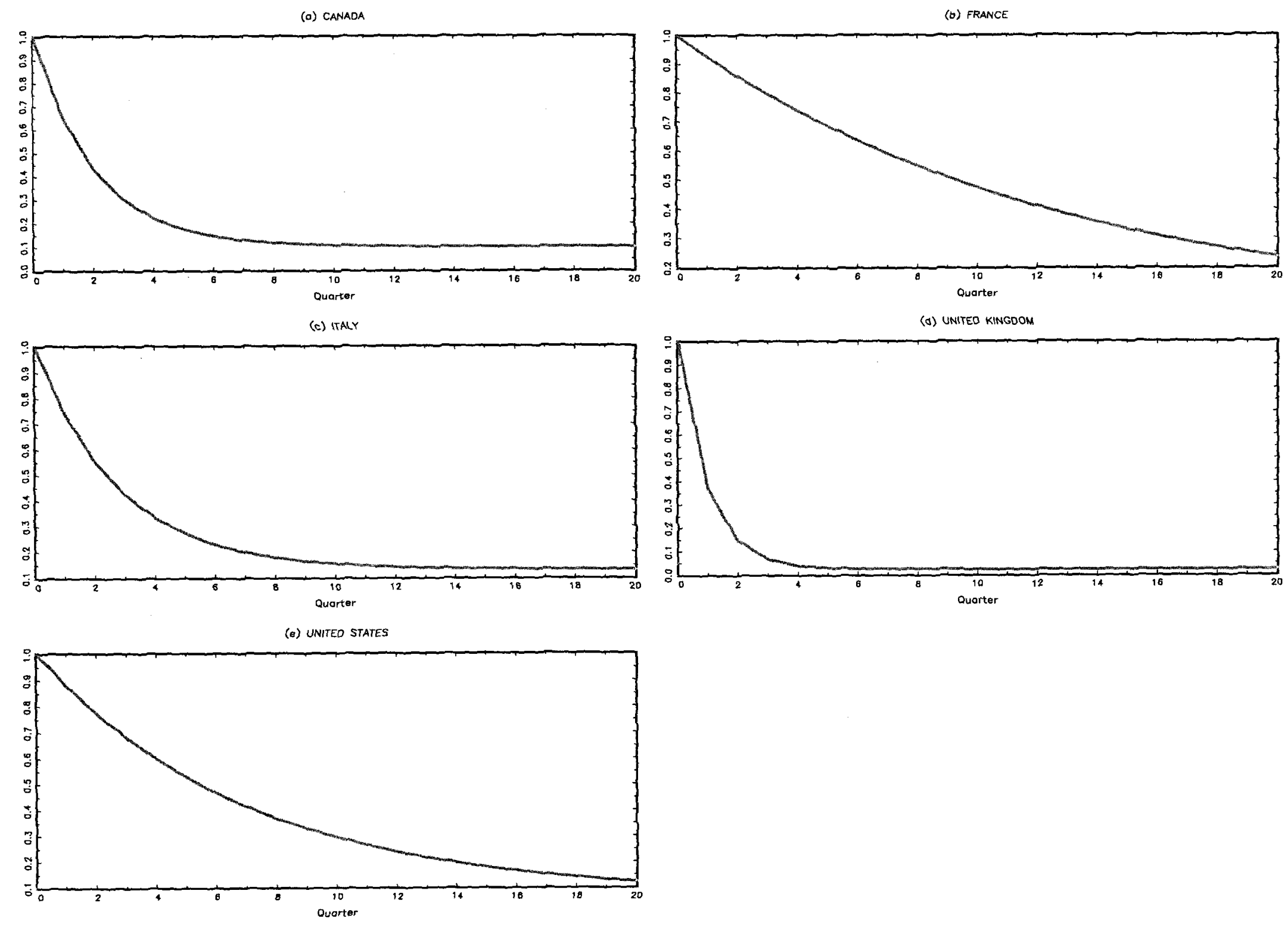